\title{
FRBRization of a Library Catalog: Better Collocation of Records, Leading to Enhanced Search, Retrieval, and Display Timothy J. Dickey
}

The Functional Requirements for Bibliographic Records (FRBR)'s hierarchical system defines families of bibliographic relationship between records and collocates them better than most extant bibliographic systems. Certain library materials (especially audio-visual formats) pose notable challenges to search and retrieval; the first benefits of a FRBRized system would be felt in music libraries, but research already has proven its advantages for fine arts, theology, and literature-the bulk of the non-science, technology, and mathematics collections. This report will summarize the benefits of FRBR to nextgeneration library catalogs and OPACs, and will review the handful of ILS and catalog systems currently operating with its theoretical structure.

Editor's note: This article is the winner of the LITA/ Ex Libris Writing Award, 2007.

$\mathrm{T}$ he following review addresses the challenges and benefits of a next-generation online public access catalog (OPAC) according to the Functional Requirements for Bibliographic Records (FRBR). ${ }^{1}$ After a brief recapitulation of the challenges posed by certain library materials-specifically, but not limited to, audiovisual materials-this report will present FRBR's benefits as a means of organizing the database and public search results from an OPAC. ${ }^{2}$ FRBR's hierarchical system of records defines families of bibliographic relationship between records and collocates them better than most extant bibliographic systems; it thus affords both library users and staff a more streamlined navigation between related items in different materials formats and among editions and adaptations of a work. In the eight years since the FRBR report's publication, a handful of working systems have been developed. The first benefits of such a system to an average academic library system would be felt in a branch music library, but research already has proven its advantages for fine arts, theology, and literature - the bulk of the non-science, technology, and mathematics collections.

\section{Current search and retrieval challenges}

The difficulties faced first, but not exclusively, by music users of most integrated library systems fall into two related categories: issues of materials formats, and issues of cataloging, indexing, and MARC record structure. Music libraries must collect, catalog, and support materi- als in more formats than anyone else; this makes their experience of the most common ILS modules-circulation, reserves, and acquisitions-by definition more complicated.

\begin{abstract}
The study of music continues to rely on the interrelated use of three distinct information formats-scores (the notated manifestation of a composer's or improviser's thought), recordings (realizations in sound, and sometimes video, of such compositions and improvisations), and books and journals (intellectual thought regarding such compositions and improvisations)-music libraries continue to require . . . collections that integrate [emphasis mine] these three information formats appropriately. ${ }^{3}$
\end{abstract}

Put a different way, "relatedness is a pervasive characteristic of music materials." 4 This is why FRBR's model of bibliographic relationships offers benefits that will first impact the music collection. ${ }^{5}$

At present, however, musical formats pose search and retrieval challenges for most ILS users, and the problem is certainly replicated with microforms and video recordings. The MARC codes distinguish between material formats, but they support only one category for sound recordings, lumping together CD, DVD audio, cassette tape, reel-toreel tape, and all other types. ${ }^{6}$ This single "sound recording" definition is easily reflected in OPACs (such as those powered by Innovative Interfaces' Millennium and Ex Libris' Aleph 500) and union catalogs (such as WorldCat. org). ${ }^{7}$ However, the distinction between sound recording formats is embedded in subfields of the 007 field, which presently cannot be indexed by many library automation systems because the subfields are not adjacent.

An even more central challenge derives from the fact that music sound recordings-such as journals and essay collections - contain within each item more than one work. Thus, for one of the central material formats collected by a music library (as well as by a public library or other academic branches), users routinely find themselves searching for a distinct subset of the item record. Perversely, though music catalogers do tend to include analytic added-entries for the subparts of a CD recording or printed score, and major ILS vendors are learning to index them, AACR2 guidelines set arbitrary cutoff points of about fifteen tracks on a sound recording, and three performable units within a score. ${ }^{8}$ Subsets of essay collections and journal runs are routinely exposed to users' searches by indexing and abstracting services and major databases, but subsets of libraries' music collections depend upon catalogers to exploit the MARC records for user access. ${ }^{9}$

Timothy J. Dickey (dickeyt@oclc.org) is a Post-Doctoral Researcher, OCLC Office of Programs and Research, Dublin, Ohio. 
In light of these pervasive bibliographic relationships, catalogers of music (again, with parallels in other subjects) have developed a distinctive approach to the MARC metadata schema. In particular, they-with their colleagues in literature, fine arts, and theology-rely upon the 700t field for uniform work titles, and upon careful authority control. ${ }^{10}$ However, once again, many major ILS portals have spotty records in affording access to library collections via these data. Innovative Interfaces' Millennium, though it clearly leads other major library products in this market, frequently frustrates music librarians (it is, of course, not alone in doing so). ${ }^{11}$ Its automatic authority control feature works poorly with (necessary) music authority records. ${ }^{12}$ And even though Innovative has been one of the first vendors to add a database index to the 700t field, partly in response to concerns expressed to the company by the Music Librarians' User Group, Millennium apparently does not allow for an appropriate level of follow-through on searching. ${ }^{13}$

An initial search by name of a major composer, for instance, yields a huge and cluttered result set containing all indexed $700 t$ fields. ${ }^{14}$ The results do helpfully include the appropriate see also references, but those references disappear in a subsidiary (limited) search. In addition, the subsidiary display inexplicably changes to an unhelpful arrangement of generic 245 fields ("Mozart, Symphonies"; "Mozart, Operas, Excerpts"). Similar challenges will be faced by other parts of an academic or large public library collection, including the literature collections (for works such as Shakespeare's plays), fine arts (for images and artists' works), and theology (for works whose uniform title is in Latin).

The OPAC interfaces of other major ILS vendors fare little better. The same search (for "Mozart") on the Emory University Library catalog (with an ILS by SirsiDynix), similarly yields a rich results set of more than one thousand records, and poses similar problems in refining the search. ${ }^{15}$ In the case of this OPAC, an index of 700t fields also exists, but it only may be searched from the inside of a single record; as with Millennium, SirsiDynix's interface will then group the next set of results confusingly by 245 fields. The Library Corporation's Carl-X apparently does not contain a $700 t$ index; the simple "Mozart" search returns a muchsimplified set of only 97 results organized by 245a fields, and thus offers a more concise set of results but avoids the most incisive index for audio-visual materials. ${ }^{16}$ Ex Libris offers a somewhat more helpful display of its more restricted results; unfortunately for the present comparison, though the detailed results set does list the "format" of all Mozart-authored items, the same term"Music" - is used for sound recordings, musical scores, and score excerpts, with no attempt logically to group the results around individual works. ${ }^{17}$ No $700 \mathrm{t}$ index appears present.

\section{THE FRBR paradigm: review of literature and theory}

From the earliest library catalogs in the modern age, the tools of bibliographic organization have sought to afford users both access to the collection and collocation of related materials. Anglo-American cataloging practice has traditionally served the first function by main entries and alternate access points and the second function by classification systems. However, as knowledge increases in scope and complexity, the systems of bibliographic control have needed to evolve. As early as the 1950s, theories were developing that sought to distinguish between the intellectual content of a work, and its often manifold physical embodiments. ${ }^{18}$ The 1961 Paris International Conference on Cataloging Principles first reified within the cataloging community a work-item distinction, though even the 1988 publication of the Anglo-American Cataloging Rules, 2nd ed., "continued to demonstrate confusion about the nature ... of works." ${ }^{19}$

Meanwhile, extensive research into the nature of bibliographic relationships groped toward a consensus definition of the entity-types that could encompass such relationships. ${ }^{20}$ Ed O'Neill and Diane Vizine-Goetz examined some one hundred editions of Smollett's The Expedition of Humphrey Clinker over a two-hundred-year span of publication history to propose a hierarchical set of definitions to define entity levels. ${ }^{21}$ The theoretical entities include the intellectual content of a work-which in the case of audio-visual works, may not even exist in any printed formats-the various versions, editions, and printings in which that intellectual content manifests itself, and the specific copies of each manifestation which a library may hold..$^{22}$ Research has discovered such clusters of bibliographically related entities for as much as 50 percent or more of all the intellectual works in any given library catalog, and as many as 85 percent of the works in a music catalog. ${ }^{23}$ This work laid the foundation for FRBR (and, once again, incidentally underscored the breadth of its applicability to, and beyond, music catalogs).

The theoretical framework of FRBR is most concisely set forth in the Final Report of the IFLA study group. The long-awaited publication traces its genesis to the 1990 Stockholm Seminar, and the resultant 1992 founding of the ILFA Study Group on Functional Requirements for Bibliographic Records. The study group set out to develop:

a framework that identifies and clearly defines the entities of interest to users of bibliographic records, the attributes of each entity, and the types of relationships that operate between entities . . . a conceptual model that would serve as the basis for relating specific attributes and relationships ... to the various tasks that users perform when consulting bibliographic records. 
The study makes no a priori assumptions about the bibliographic record itself, either in terms of content or structure. ${ }^{24}$

In other words, the intention of the group's deliberations and the Final Report is to present a model for understanding bibliographic entities and the relationships between them to support information organization tools. It specifically adopts an approach that defines classes of entities based upon how users, rather than catalogers, approach bibliographic records-or, by natural extension, any system of metadata.

The FRBR hierarchical entities comprise a fourfold set of definitions:

- Work: "a distinct intellectual or artistic creation";

- Expression: "the intellectual or artistic realization of a work" in any combination of forms (including editions, arrangements, adaptations, translations, performances, etc.);

- Manifestation: "the physical embodiment of an expression of a work"; and

- Item: "a single exemplar of a manifestation."25

Examples of these hierarchical levels abound in the bibliographic universe, but frequently music offers the quickest examples:

- Work: Mozart's Die Zauberflöte (The Magic Flute)

- Work: Puccini's La Bohéme

- Expression: The composer's complete musical score (1896)

- Manifestation: Edition of the score printed by Ricordi in 1897

- Expression: An English language edition for piano and voices

- Expression: A performance by Mirella Freni, Luciano Pavarotti, and the Berlin Philharmonic Orchestra (October 1972)

- Manifestation: A recording of this perfor mance released on 331/3 RPM sound discs in 1972 by London Records

- Manifestation: A re-release of the same per formance on compact disc in 1987 by London Records

- Item: The copy of the compact disc held by the Columbus Metropolitan Library

- Item: The copy of the compact disc held by the University of Cincinnati

In fact, LIS research has tended to demonstrate what music librarians have always understood-that relatedness among items and complexity of families is most prevalent in audio-visual collections. Even before the IFLA Report had been penned, Sherry Vellucci had set out the task: "To create new catalog structures that better serve the needs of the music user community, it is important first to understand the exact nature and complexity of the materials to be described in the catalog." 26 Even limiting herself to musical scores alone (that is, no recordings or monographs), Vellucci found that more than 94.8 percent of her sample exhibited at least one bibliographic relationship with another entity in the collection; she further related this finding to the very "inherent nature of music, which requires performance for its aural realization," as opposed to, for example, monographic book printing. ${ }^{27}$

Vellucci and others have frequently commented on how the relatedness of manifestations - in different formats, arrangements, and abridgements-of musical works continues to be a problem for information retrieval in the world of music bibliography. ${ }^{28}$

Musical works have been variously and industriously described by musicologists and music bibliographers. Yet, in the information retrieval domain [and, I might add, under both $A A C R$ and $A A C R 2]$... systems for bibliographic information retrieval . . . have been designed with the document as the key entity, and works have been dismissed as too abstract ... ${ }^{29}$

The work is the access point many users will bring-in their minds, and thus in their queries-to a system. They intend, however, to discover, identify, and obtain specific manifestations of that work. Very recently, research has begun to demonstrate that the FRBR model can offer specific advantages to music retrieval in cases such as these: "the description of bibliographic data in a FRBR-based database leads to less redundancy and a clearer presentation of the relationships which are implicit in the traditional databases found in libraries today." 30 Explorations of the theory in view of the benefits to other disciplines, such as audio-visual and other graphic materials, maps, oral literature, and rare books, have appeared in the literature as well. ${ }^{31}$ The admitted weakness of the FRBR theory, of course, is that it remains a theory at its inception, with still preciously few working applications.

\section{FRBR applications}

Working implementations of FRBR to catalogs, OPACs, and ILSs are still relatively few but promise much for the future. The FRBR theoretical framework has remained an area of intense research at OCLC, which has even led to some prototype applications and, very recently, deployment in the WorldCat Local interface. ${ }^{32}$ A scattered few other researchers have crafted FRBR catalogs and catalog displays for their own ends; the Library of Congress has a prototype as well. Innovative, the leading academic ILS vendor, announced a FRBR feature for 2005 release, 
yet shelved the project for lack of a beta-testing partner library. ${ }^{33}$ Ex Libris' Primo discovery tool, one other complete ILS (by Visionary Technologies for Library Systems, or VTLS), and the National Library of Australia, have each deployed operational FRBR applications. ${ }^{34}$ The number of projects testifies to the high level of interest among the cataloging and information science communities, while the relatively small number of successful applications testifies to the difficulties faced.

OCLC has engaged in a number of research projects and prototypes in order to explore ways that FRBRization of bibliographic records could enhance information access. OCLC Research frequently notes the potential streamlining of library cataloging by FRBRization; in addition they have experienced "superior presentation" and "more intuitive clustering" of search results when the model is incorporated into systems..$^{35}$ Work-level definitions stand behind such OCLC Research prototypes as Audience Level, Dewey Browser, FictionFinder, xISBN, and Live Search. In every case, researchers determined that, though it was very difficult to automate any identification of expressions, application of work-level categories both simplifies and improves search result sets. ${ }^{36}$

An algorithm common to several of these applications is freely available as an open source application, and now as a public interface option in OCLC's WorldCat Local. ${ }^{37}$ The algorithm creates an author/title key to cluster worksets (often at a higher level than the FRBR work, as in the case of the two distinct works that are the book and screenplay for Gone with the Wind). In the public search interface, the results sets may be grouped at the work level; users may then execute a more granular search for "all editions," an option that then displays the group of expressions linked to the work record. Unfortunately, as the software does not use 700t fields (its intention is to travel up the entity hierarchy, and it uses the $1 x x, 24 x$, and 130 fields), its usefulness in solving the above challenges may not be immediate. A somewhat similar application (though Merrilee Proffitt declares it not to be a FRBR product) was RedLightGreen, a user interface for the exRLG union catalog based upon quasi-FRBR clustering. ${ }^{38}$

The reports from designers of other automated systems offer interesting commentaries on the process. The team building an automatically FRBRized database and user interface for AustLit-a new union collection of Australian literature among eight academic libraries and the National Library of Australia-acknowledged some difficulty with non-monographic works such as poems, though the majority of their database consisted of simpler work-manifestation pairs. ${ }^{39}$ Based on strongly positive user feedback ("The presentation of information about related works [is] both useful and comprehensible"), a similar application was attempted on the Australian national music gateway MusicAustralia; it is unclear whether the project was shelved due to difficulties in automating the FRBRization process. ${ }^{40}$

One recent application created for the Perseus Digital Library adopts a somewhat different approach. ${ }^{41}$ Rather than altering previously created MARC records to allow hierarchical relationships to surface, this team created new records using crosswalks between MARC and, for instance, MODS, for work-level records. They claim some moderate level of success; though once again, their discussion of the process is more illuminating than their product. Mimno and Crane successfully allowed a single manifestation-level record to link upwards to many expressions, a necessary analytic feature especially for dealing with sound recordings. They did practically demonstrate the difficulty of searching elements from different levels of the hierarchy at the same time (such as work title and translator), a complication predicted by Yee. ${ }^{42}$

Three ILS vendors have released products that use the FRBR model: Portia (VisualCat), Ex Libris (Primo), and VTLS (Virtua)..$^{43}$ The first product, a cataloging utility from a smaller player in the vendor market, claims to incorporate FRBR into its metadata capture, yet the information available does not explain how, nor do they offer an OPAC to exploit it. The 2007 release of Ex Libris' Primo offers what the company calls "FRBR groupings" of results. ${ }^{44}$ This discovery tool is not itself an ILS, but promises to interoperate with major existing ILS products to consolidate search results. It remains unclear at this time how Ex Libris' "standard FRBR algorithms" actually group records; the single deployment in the Danish Royal Library allows searching for more records with the same title, for instance, but does not distinguish between translations of the same work. ${ }^{45}$

VTLS, on the other hand, has since 2004 offered a complete product that has the potential to modify existing MARC records-via local linking tags in the 001 and 004 fields-to create FRBR relationships. ${ }^{46}$ Their own studies agreed with OCLC that a subset, roughly 18 percent, of existing catalog records (most heavily concentrated in music collections) would benefit from the process, and they thus allow for "mixed" catalogs, with only subsets (or even individually selected records) to be FRBRized. The company's own information suggests relatively simple implementation by library catalogers, coupled with robust functionality for users, and may be the leading edge of the next generation of catalog products.

\section{FRBR solutions}

The ILFA Study Group, following its user-centered approach, set out a list of specific tasks that users of a computer-aided catalog should be able to accomplish: 
- to find all manifestations embodying certain criteria, or to find a specific manifestation given identifying information about it;

- to identify a work, and to identify expressions and manifestations of that work;

- to select among works, among expressions, and among manifestations; and

- to obtain a particular manifestation once selected.

It seems clear that the FRBR model offers a framework of relationships that can aid each task. Unfortunately, none of the currently available commercial solutions may be in themselves completely applicable for a single library. The OCLC Work-set Algorithm is open source, as well as easily available through WorldCat Local, but it only works to create super-work records; it also ignores the 700t field so crucial to many of the issues noted above. None of the other home-grown applications may have code available to an institution. The Virtua module from VTLS offers a very tempting solution, but may require a change of vendor. ${ }^{47}$

Either adapting one of these solutions or designing a local application, then, raises the question: What would the ideal system entail? Catalog FRBRization will transpire in two segments: enhancing the existing catalog to add bibliographic relationships to surface in the retrieval phase, and designing or adaptating a new interface and display to reflect the relationships. ${ }^{48}$ The first task may prove the more formidable, due to the size of even a modest catalog database and the difficulties often observed in automating such a task; while the librarians constructing the AustLit system found a relatively high percentage of records could be transferred en masse, the OCLC Research team had difficulty automatically pinpointing expressions from current MARC records. ${ }^{49}$

Despite current technology trends toward users' application of tags, reviews, and other metadata, a task as specialized as adding bibliographic relationships to the catalog demands specialized cataloging professionals. ${ }^{50}$ The best approach within a current library structure may be to create a single new position to head the project and to act as liaison with cataloging staff in the various branches and with vendor staff, if applicable. Each library branch may judge on its own the proportions of records to FRBRize, beginning with high-traffic works and authors, those for whom search results tend to be the most overwhelming and confusing to users. Each branch can be responsible for allocation of cataloging staff effort to the process, and will thus have specialist oversight of subsets of the database.

Three technical solutions to actually changing the database structure have been attempted in the literature to date: incrementally improving the existing MARC records to better reflect bibliographic relationships, add- ing local linking tags, and simply creating new metadata schemas. The VTLS solution of adding local linking tags seems most appropriate; relationships between records are created and maintained via unique identifiers and linking statements in the 001 and 004 fields. ${ }^{51}$ OCLC's open source software could expedite the creation of work-level records, and the creation of expression-level records will be made easier by the large amount of bibliographic information already present in the current catalog. Wherever possible, cataloging staff also should take the opportunity to verify or create links to authority files so as to enhance retrieval. ${ }^{52}$

Creating a new catalog display option could be accomplished via additions to current OPAC coding, either by adopting WorldCat Local or by designing parts of a new local interface. It need not even require a complete revision; the single site (UCL) currently deploying VTLS' FRBRized interface maintains a mixed catalog and offers, once again, a highly intuitive model. ${ }^{53}$ When a searcher comes across a bibliographic record for which FRBR linking is available, they may click a link to open a new display screen. We should strive, however, to use simple interface statements such as "View all different kinds of holdings," "This work has x editions, in y languages" or "This version of the work has been published z times" (both the OCLC prototype and the AustLit Gateway offer such helpful and user-friendly statements). Though the foundational work of both Tillett and Smiraglia focused upon taxonomies of relationships, the hierarchical structure of the IFLA proposal should remain at the forefront of the display, with a secondary organization by type of relationship or type of entity. Rather than adopting a design which automatically refreshes at each click, a tree organization of the display should be more user-friendly, allowing users to maintain a visual sense of the organization that they are encountering (see Appendix for screenshots of this type of tree display). ${ }^{54}$ Format information should be included in the display, as an indication of a users' primary category, as well as a distinction among expressions of a work.

With these changes, the library catalog will begin to afford its users better access to many of its core collections. FRBRization of even part of the catalog-concentrating on high-incidence authors, as identified by subject specialists-will allow it better to reflect, and collocate, items within the families of bibliographic relationships that have been acknowledged a part of library collections for decades. This increased collocation will begin to counteract the pitfalls of mere keyword searching on the part of users, especially in conjunction with renewed authority work. Finally, FRBR offers a display option in a revamped OPAC that is at the same time simpler than current result lists, and more elegant in its reflection of relatedness among items. Each feature should better 
enable the users of our catalog to find, select, and obtain appropriate resources, and will bring our libraries into the next generation of cataloging practice.

\section{References and notes}

1. IFLA Committee on the Functional Requirements for Bibliographic Records, Final Report (Munich: K. G. Saur, 1998); see also http://www.ifla.org/VII/s13/wgfrbr/bibliography.htm (accessed Mar. 10, 2007).

2. This paper began as a graduate research assignment for LIS 60640 (Library Automation), in the Kent State University MLIS program, March 19, 2007. My thanks to Jennifer Hambrick, Nancy Lensenmayer, and Joan Lippincott, for their helpful comments on earlier drafts. The curricular assignment asked for a library automation proposal in a specific library setting; the original review contained a set of recommendations concerning FRBR through the lens of a (fictional) medium-sized academic library system, that of St. Hildegard of Bingen Catholic University. As will be noted below, the branch Music Library typically serves a small population of music majors (graduate and undergraduate) within such an institution, but also a large portion of the student body that use the library's collection to support their music coursework and arts distribution requirements. Any music library's proportion of the overall system's holdings may be relatively small, but will include materials in a diverse set of formats: monographs, serials, musical scores, sound recordings in several formats (cassette tapes, LPs, CDs, and streaming audio files), and a growing collection of video recordings, likewise in several formats (VHS, laser discs, and DVD). It thus offers an early test case for difficulties with an automated library system.

3. Dan Zager, "Collection Development and Management," Notes-Quarterly Journal of the Music Library Association 56, no. 3 (March 2000): 569.

4. Sherry L. Velluci, "Music Metadata and Authority Control in an International Context," Notes-Quarterly Journal of the Music Library Association 57, no. 3 (Mar. 2001): 541.

5. The OPAC for the University of Huddersfield Library system famously first deployed a search option for related items ("Did you mean . . . ?"); http://www.hud.ac.uk/cls (accessed July 10, 2007). FRBR not only offers the related item search, but also logically groups related works throughout the library cata$\log$.

6. Allyson Carlyle demonstrated empirically that users value an object's format as one of the first distinguishing features: "User Categorization of Works: Toward Improved Organization of Online Catalog Displays," Journal of Documentation 55, no. 2 (Mar. 1999): 184-208 at 197.

7. Millennium will feature heavily in the following discussion, both because of its position leading the academic library automation market (being adopted wholesale by, for instance, the Ohio statewide academic library consortium), and because it was the subject of the original paper.

8. See Alastair Boyd, "The Worst of Both Worlds: How Old Rules and New Interfaces Hinder Access to Music," CAML Review 33, no. 3 (Nov. 2005), http://www.yorku.ca/caml/ review/33-3/both_worlds.htm (accessed Mar. 12, 2007); Michael
Gorman and Paul W. Winkler, eds., Anglo-American Cataloging Rules, 2nd ed. (Chicago: ALA, 1988).

9. In the past few years, a small subset of the search literature has described technical efforts to develop search engines that can query by musical example; see J. Stephen Downie, "The Scientific Evaluation of Music Information Retrieval Systems: Foundations and Future," Computer Music Journal 28, no. 2 (Summer 2004): 12-23. A company called Melodis Corporation has recently announced a successful launch of a query-by-humming search engine, though a verdict from the music community remains out; http:/ /www.midomi.com (accessed Jan. 31, 2007).

10. See Velluci, "Music Metadata and Authority Control in an International Context"; Richard P. Smiraglia, "Uniform Titles for Music: An Exercise in Collocating Works," Cataloging and Classification Quarterly 9, no. 3 (1989): 97-114; Steven H. Wright, "Music Librarianship at the Turn of the Century: Technology," Notes-Quarterly Journal of the Music Library Association 56, no. 3 (Mar. 2000): 591-97. Each author builds upon the foundational work of Barbara Tillett, "Bibliographic Relationships: Toward a Conceptual Structure of Bibliographic Information Used in Cataloging" (Ph.D. diss., University of California at Los Angeles, 1987).

11. "At conferences, [my colleagues] are always groaning if they are a Voyager client," interview with an academic music librarian by the author, Feb. 9, 2007.

12. Several prominent music librarians only discovered that Innovative's system had such a feature when instances of the automatic system's changing carefully crafted music authority records were discovered; Mark Sharff (Washington University in St. Louis) and Deborah Pierce (University of Washington), postings to Innovative Music Users' Group electronic discussion list, Oct. 6, 2006, archive accessed Feb. 1, 2007.

13. Music librarians are the only subset of the Millennium users to have formed their own Innovate Users' Group. SirsiDynix has a separate Users' Group for STM librarians, and Ex Libris hosts a Law Librarians' Users' Group, two other groups whose interaction with the ILS poses discipline-specific challenges.

14. Searches were tested on the The Ohio State University Libraries' OPAC , http://library.osu.edu (accessed Mar. 10, 2007).

15. http://www.emory.edu/libraries.cfm (accessed June 27, 2007).

16. Searches performed on the library of Oklahoma State University, http://www.library.okstate.edu (accessed June 27, 2007); TLC has considered making FRBRization a possible feature of their product. They offer some concatenation of "intellectually similar bibliographic records," and "TLC continues to monitor emerging FRBR standards"; Don Kaiser, personal communication to the author, July 8,2007 . I was unable to reach representatives of SirsiDynix on this issue.

17. Searches performed on the MIT Library catalog, powered by ALEPH 500 http://libraries.mit.edu (accessed June 27, 2007).

18. Eva Verona, "Literary Unit versus Bibliographic Unit [1959]," in Foundations of Descriptive Cataloging, ed. Michael Carpenter and Elaine Svenonius, 155-75 (Littleton, Colo.: Libraries Unlimited, 1985), and Seymour Lubetzky, Principles of Cataloging, Final Report Phase I: Descriptive Cataloging (Los Angeles: Institute for Library Research, 1969), are usually credited with 
the foundational work on such theories; see Richard P. Smiraglia, The Nature of "A Work": Implications for the Organization of Knowledge (Lanham, Md.: Scarecrow, 2001), 15-33, to whom the following overview is indebted.

19. Anglo-American Cataloging Rules, cited in Smiraglia, The Nature of "A Work," 33.

20. Among the many library and information science thinkers contributing to this body of research, the most prominent have been Patrick Wilson, "The Second Objective" in The Conceptual Foundations of Descriptive Cataloging, ed. Elaine Svenonius, 5-16 (San Diego: Academic Publ., 1989); Edward T. O'Neill and Diane Vizine-Goetz, "Bibliographic Relationships: Implications for the Function of the Catalog," in The Conceptual Foundations of Descriptive Cataloging, ed. Elaine Svenonius, 167-79 (San Diego: Academic Publ., 1989); Barbara Ann Tillett, "Bibliographic Relationships: Toward a Conceptual Structure of Bibliographic Information Used in Cataloging" (Ph.D. diss, University of California, Los Angeles, 1987); eadem, "Bibliographic Relationships," in Relationships in the Organization of Knowledge, Carol A. Bean and Rebecca Green, eds. , 19-35 (Dordrecht: Kluwer, 2001) (summary of her dissertation findings on 19-20); Martha M. Yee, "Manifestations and Near-Equivalents: Theory with Special Attention to Moving-Image Materials," Library Resources and Technical Services 38, no. 3 (1994): 227-55.

21. O'Neill and Vizine-Goetz, "Bibliographic Relationships"; see also Edward T. O'Neill, "FRBR: Application of the Entityrelationship Model to Humphrey Clinker," Library Resources and Technical Services 46, no. 4 (Oct. 2002): 150-59.

22. Theorists in music semiotics who have more or less profoundly influenced music librarians' view of their materials include Jean-Jacques Nattiez, Music and Discourse: Toward a Semiology of Music, trans. by Carolyn Abbate (Princeton, N.J.: Princeton Univ. Pr., 1990), and Lydia Goehr, The Imaginary Museum of Musical Works (New York: Oxford Univ. Pr., 1992). See also Smiraglia, The Nature of "A Work," 64. For a concise overview of how semiotic theory has influenced thinking about literary texts, see W. C. Greetham, Theories of the Text (Oxford: Oxford Univ. Pr., 1999), 276-325.

23. Studies have found families of derivative bibliographic relationships in 30.2 percent of all WorldCat records, 49.9 percent of records in the catalog of Georgetown University Library, 52.9 percent in the Burke Theological Library (Union Theological Seminary), 57.9 percent of theological works in the New York University Library, and 85.4 percent in the Sibley Music Library at the Eastman School of Music (University of Rochester). See Smiraglia, The Nature of "A Work," 87, who cites Richard P. Smiraglia and Gregory H. Leazer, "Derivative Bibliographic Relationships: The Work Relationship in a Global Bibliographic Database," Journal of the American Society for Information Science 50 (1999): 493-504; Richard P. Smiraglia, "Authority Control and the Extent of Derivative Bibliographic Relationships" (Ph.D. diss., University of Chicago, 1992); Richard P. Smiraglia, "Derivative Bibliographic Relationships among Theological Works," Proceedings of the 62nd Annual Meeting of the American Society for Information Science (Medford, N.J.: Information Today, 1999): 497-506; and Sherry L. Vellucci, "Bibliographic Relationships among Musical Bibliographic Entities: A Conceptual Analysis of Music Represented in a Library Catalog with a Taxonomy of the Relationships" (D.L.S. diss., Columbia University, 1994).

24. IFLA, Final Report, 2-3.
25. Ibid, 16-23.

26. Sherry L. Vellucci, Bibliographic Relationships in Music Catalogs (Lanham, Md.: Scarecrow, 1997), 1.

27. Ibid, 238; 251.

28. Vellucci, "Music Metadata"; Richard P. Smiraglia, "Musical Works and Information Retrieval," Notes: Quarterly Journal of the Music Library Association 58, no. 4 (June 2002). Patrick Le Boeuf notes that users of music collections often use the single word "score" to indicate any one of the four FRBR entities; "Musical Works in the FRBR Model or 'Quasi la Stessa Cosa': Variations on a Theme by Umberto Eco," in Functional Requirements for Bibliographic Records (FRBR): Hype or Cure-All? ed. Patrick Le Boeuf, 103-23 at 105-06 (New York: Haworth, 2005).

29. Smiraglia, "Musical Works and Information Retrieval," 2.

30. Marte Brenne, "Storage and Retrieval of Musical Documents in a FRBR-based Library Catalogue" (Masters' Thesis, Oslo University College, 2004), 79. See also John Anderies, "Enhancing Library Catalogs for Music," paper presented at the Conference on Music and Technology in the Liberal Arts Environment, Hamilton College, June 22, 2004; PowerPoint presentation accessed Mar. 12, 2007, from http://academics. hamilton.edu/conferences/musicandtech/Presentations/Catalog-Enhancements.ppt; Boyd, "The Worst of Both Worlds."

31. See the extensive bibliography compiled by IFLA, Cataloging Division: "FRBR Bibliography," http://www.ifla.org/ VII/s13/wgfrbr.bibliography.htm (accessed Mar. 10, 2007).

32. The first ILS deployment of the WorldCat Local application using FRBR is with the University of Washington Libraries: http:/ /www.lib.washington.edu (accessed June 27, 2007).

33. Innovative Interfaces, Inc., "Millennium 2005 Preview: FRBR Support," INN-Touch (June 2004), 9. Interestingly, the onepage advertisement for the new service chose a musical work, Puccini's opera La Bohème, to illustrate how the sorting would work. Innovative Interfaces booth staff at the ALA National Conference, Washington, D.C., June 24, 2007, told the author the company has moved in a different development direction now (investing more heavily in faceted browsing).

34. Denmark's Det Kongelige Bibliotek has been the first Ex Libris partner library to deploy Primo, http://www.kb.dk/en (accessed July 10, 2007). The VTLS system has been operating since 2004 at the Université catholique de Louvain, http:// www.bib.ucl.ac.be (accessed Mar. 15, 2007). For Austlit, see http:/ / www.austlit.edu.au (accessed Mar. 14, 2007).

35. Rick Bennett, Brian F. Lavoie, and Edward T. O'Neill, "The Concept of a Work in WorldCat: An Application of FRBR," Library Collections, Acquisitions, and Technical Services 27, no. 1 (Spring 2003): 45-60. Work-level records allow manifestation and item records to inherit labor-intensive subject classification metadata; Eric Childress, "FRBR and OCLC Research," paper presented at the University of North Carolina-Chapel Hill, Apr. 10, 2006, http://www.oclc.org/research/presentations/ childress/20060410-uncch-sils.ppt (accessed Mar. 12, 2007).

36. Thomas B. Hickey, Edward T. O'Neill, and Jenny Toves, "Experiments with the IFLA Functional Requirements for Bibliographic Records (FRBR)," D-Lib 8, no. 9 (Sept. 2002), http:/ / www.dlib.org/dlib/september02/hickey/09hickey.html (accessed Mar. 12, 2007).

37. Thomas B. Hickey and Jenny Toves, "FRBR Work-Set Algorithm," Apr. 2005 report, http://www.oclc.org/research/ projects/frbr/default.htm (accessed Mar. 12, 2007); algorithm 
available at http:/ / www.oclc.org/research/projects/frbr/algorithm.htm. On WorldCat Local, see above, note 32.

38. Merrilee Proffitt, "RedLightGreen: FRBR between a Rock and a Hard Place," http:/ / www.ala.org/ala/alcts/alctsconted/ presentations/Proffitt.pdf (accessed Mar. 12, 2007). RedLight Green has been discontinued, and some of its technology incorporated into WorldCat Local.

39. http://www.austlit.edu.au (accessed Mar. 14, 2007), but unfortunately a subscription database at this time, and thus unavailable for operational comparison. See Marie-Louise Ayres, "Case Studies in Implementing Functional Requirements for Bibliographic Records: AustLit and MusicAustralia," ALJ: The Australian Library Journal 54, no. 1 (Feb. 2005): 43-54, http:/ / www.nla.gov.au/nla/staffpaper/2005/ayres1.html (accessed Mar. 12, 2007).

40. Ibid.

41. See David Mimno and Gregory Crane, "Hierarchical Catalog Records: Implementing a FRBR Catalog," D-Lib 11, no. 10 (Oct. 2005); http://www.dlib.org/dlib/october05/ crane/10crane.html (accessed Mar. 12, 2007).

42. Ibid. See also Martha M. Yee, "FRBRization: A Method for Turning Online Public Finding Lists into Online Public Catalogs," Information Technology and Libraries 24, no. 3 (2005): 77-95, http:/ / repositories.cdlib.org/postprints/715 (accessed Mar. 12, 2007).

43. Portia, "VisualCat Overview," http://www.portia.dk/ pubs/visualcat/present/visualcatoverview20050607.pdf (accessed Mar. 14, 2007); VTLS, Inc., "Virtua," http:/ / www.vtls. com/brochures/virtua.pdf (accessed Mar. 14, 2007).

44. http://www.exlibrisgroup.com/primo_orig.htm (accessed July 10, 2007).

45. Syed Ahmed, personal communication to the author, July 10, 2007; searches run July 10, 2007, on http://www.kb.dk/en. The library's holdings of manifestations of Mozart's Singspiel opera, The Magic Flute, run to four different groupings on this catalog: one under the title "Die Zauberflöte," one under the title "La flute enchantée: Opéra fantastique en 4 actes," and two separate groups under the title "Tryllefløtjen."

46. "VTLS Announces First Production Use of FRBR," http:// www.vtls.com/Corporate/Releases/2004/6.shtml (accessed Mar. 14, 2007). Unfortunately, though this press release indicates commitments on the part of the Universite catholique de Louvain and Vaughan Public Libraries (Ontario, Canada) to use fully FRBRized catalogs, only the first is operating in this mode as of July 2007, and with only a subset of its catalog adapted.

47. Virtua is not interoperable, for instance, with any of Innovative's other ILS modules, which continue to dominate a number of larger academic consortia; John Espley, VTLS Inc. Director of Design, personal communication to the author, Mar. 15, 2007.

48. See Allyson Carlyle, "Fulfilling the Second Objective in the Online Catalog: Schemes for Organizing Author and Work Records into Usable Displays," Library Resources and Technical Services 41, no. 2 (1997): 79-100.

49. Even at the work-level, Yee distinguished fully eight different places in a MARC record in which the identity of a work may be located, "FRBRization," 79-80.

50. Gregory Leazer and Richard P. Smiraglia imply that cataloger-based "maps" of bibliographic relationships are inadequate; "Bibliographic Families in the Library Catalog: A Quali- tative Analysis and Grounded Theory," Library Resources and Technical Services 43, no. 4 (1999): 191-212. The cataloging failures they describe, however, are more a result of inadequacies in the current rules and practice, and do not really prove that catalogers have failed in the task of creating useful systems.

51. Vinood Chacra and John Espley, "Differentiating Libraries though Enriched User Searching: FRBR As the Next Dimensions in Meaningful Information Retrieval," PowerPoint presentation, http://www.vtls.com/Corporate/FRBR.shtml (accessed Mar. 10, 2007).

52. See Yee, "FRBRization."

53. http://www.bib.ucl.ac.be (accessed Mar. 15, 2007).

54. Not only does the Ex Libris Primo application need clickthroughs, it creates a new window for an extra step before presenting a new group of records.

\section{Bibliography}

Anderies, John. "Enhancing Library Catalogs for Music." Paper presented at the Conference on Music and Technology in the Liberal Arts Environment, Hamilton College, June 22, 2004; http: / / academics.hamilton.edu/conferences / musicandtech/Presentations/Catalog-Enhancements.ppt (accessed Mar. 12, 2007).

Ayres, Marie-Louise. "Case Studies in Implementing Functional Requirements for Bibliographic Records: AustLit and MusicAustralia." ALJ: The Australian Library Journal 54, no. 1 (Feb. 2005): 43-54; http://www.nla.gov.au/nla/staffpaper/2005/ ayres1.html (accessed Mar. 12, 2007).

Bennett, Rick, Brian F. Lavoie, and Edward T. O'Neill. "The Concept of a Work in WorldCat: An Application of FRBR." Library Collections, Acquisitions, and Technical Services 27, no. 1 (Spring 2003): 45-60.

Boyd, Alistair. "The Worst of Both Worlds: How Old Rules and New Interfaces Hinder Access to Music." CAML Review 33, no. 3 (Nov. 2005); http: / / www.yorku.ca/caml/review/33-3/ both_worlds.htm (accessed Mar. 12, 2007).

Brenne, Marte. "Storage and Retrieval of Musical Documents in a FRBR-based Library Catalogue." Masters' Thesis, Oslo University College, 2004.

Carlyle, Allyson. "Fulfilling the Second Objective in the Online Catalog: Schemes for Organizing Author and Work Records into Usable Displays," Library Resources and Technical Services 41, no. 2 (1997): 79-100.

"User Categorization of Works: Toward Improved Organization of Online Catalog Displays." Journal of Documentation 55, no. 2 (Mar. 1999): 184-208

Chacra, Vinood, and John Espley. "Differentiating Libraries though Enriched User Searching: FRBR As the Next Dimensions in Meaningful Information Retrieval." PowerPoint presentation, http://www.vtls.com/Corporate/FRBR.shtml (accessed Mar. 10, 2007).

Childress, Eric. "FRBR and OCLC Research." Paper presented at the University of North Carolina-Chapel Hill, Apr. 10, 2006; http:/ /www.oclc.org/research/presentations/ childress/20060410-uncch-sils.ppt (accessed Mar. 12, 2007).

Hickey, Thomas B., and Edward O'Neill. "FRBRizing OCLC's WorldCat." In Functional Requirements for Bibliographic Records 
(FRBR): Hype or Cure-All? ed. Patrick Le Boeuf, 239-251. New York: Haworth, 2005.

Hickey, Thomas B., and Jenny Toves. "FRBR Work-Set Algorithm." Apr. 2005 report; http://www.oclc.org/research/ frbr (accessed Mar. 12, 2007).

Hickey, Thomas B., Edward T. O'Neill, and Jenny Toves, "Experiments with the IFLA Functional Requirements for Bibliographic Records (FRBR)," D-Lib 8, no. 9 (Sept. 2002); http://www.dlib.org/dlib/september02/hickey/09hickey. html (accessed Mar. 12, 2007).

IFLA Study Group on the Functional Requirements for Bibliographic Records. Functional Requirements for Bibliographic Records: Final Report. Munich: K. G. Saur, 1998.

Layne, Sara Shatford. "Subject Access to Art Images." In Introduction to Art Image Access: Issues, Tools, Standards, Strategies, Murtha Baca, ed., 1-18. Los Angeles: Getty Research Institute, 2002.

Leazer, Gregory, and Richard P. Smiraglia. "Bibliographic Families in the Library Catalog: A Qualitative Analysis and Grounded Theory." Library Resources and Technical Services 43, no. 4 (1999): 191-212.

Le Boeuf, Patrick. "Musical Works in the FRBR Model or 'Quasi la Stessa Cosa': Variations on a Theme by Umberto Eco." In Functional Requirements for Bibliographic Records (FRBR): Hype or Cure-All? Patrick Le Boeuf, ed., 103-23 New York: Haworth, 2005.

Markey, Karen. Subject Access to Visual Resources Collections: A Model for Computer Construction of Thematic Catalogs. New York: Greenwood, 1986.

Mimno, David, and Gregory Crane. "Hierarchical Catalog Records: Implementing a FRBR Catalog." D-Lib 11, no. 10 (Oct. 2005); http://www.dlib.org/dlib/october05/crane/10crane. html (accessed Mar. 12, 2007).

O'Neill, Edward T. "FRBR: Application of the Entity-relationship Model to Humphrey Clinker." Library Resources and Technical Services 46, no. 4 (Oct. 2002): 150-59.

O'Neill, Edward T., and Diane Vizine-Goetz. "Bibliographic Relationships: Implications for the Function of the Catalog." in The Conceptual Foundations of Descriptive Cataloging. Elaine Svenonius, ed., 167-79. San Diego: Academic Publ., 1989.

Proffitt, Merrilee. "RedLightGreen: FRBR Between a Rock and a Hard Place." Paper presented at the 2004 ALA Annual Con- ference, Orlando, Fla.; http://www.ala.org/ala/alcts/alctsconted/presentations/Proffitt.pdf (accessed Mar. 12, 2007).

Smiraglia, Richard P. Bibliographic Control of Music, 1897-2000. Lanham, Md.: Scarecrow and Music Library Association, 2006.

"Content Metadata: An Analysis of Etruscan Artifacts in a Museum of Archaeology." Cataloging and Classification Quarterly, 40, no. 3/4 (2005): 135-51.

"Musical Works and Information Retrieval," Notes: Quarterly Journal of the Music Library Association 58, no. 4 (June 2002): 747-64.

. The Nature of "A Work": Implications for the Organization of Knowledge. Lanham, Md.: Scarecrow, 2001.

" "Uniform Titles for Music: An Exercise in Collocating Works." Cataloging and Classification Quarterly 9, no. 3 (1989): 97-114.

Tillett, Barbara Ann. "Bibliographic Relationships." in Relationships in the Organization of Knowledge. Carol A. Bean and Rebecca Green, eds., 19-35. Dordrecht: Kluwer, 2001.

Vellucci, Sherry L. Bibliographic Relationships in Music Catalogs. Lanham, Md.: Scarecrow, 1997.

"Music Metadata and Authority Control in an International Context." Notes-Quarterly Journal of the Music Library Association 57, no. 3 (Mar. 2001): 541-54.

Wilson, Patrick. "The Second Objective." In The Conceptual Foundations of Descriptive Cataloging. Elaine Svenonius, ed., 5-16. San Diego: Academic Publ., 1989.

Wright, H. S. "Music Librarianship at the Turn of the Century: Technology." Notes: Quarterly Journal of the Music Library Association 56, no. 3 (Mar. 2000): 591-97.

Yee, Martha M. "FRBRization: A Method for Turning Online Public Finding Lists into Online Public Catalogs." Information Technology and Libraries 24, no. 3 (2005): 77-95; http:/ / repositories.cdlib.org/postprints/713 (accessed Mar. 12, 2007).

. "Manifestations and Near-Equivalents: Theory with Special Attention to Moving-Image Materials." Library Resources and Technical Services 38, no. 3 (1994): 227-55.

Zager, Daniel. "Collection Development and Management." Notes: Quarterly Journal of the Music Library Association 56, no. 3 (2000): 567-73. 


\section{Appendix: Examples of a FRBRized Tree Display}

A search on Also sprach Zarathustra on the online public access catalog for the Universite catholique de Louvain, with results FRBRized. (A VTLS OPAC).

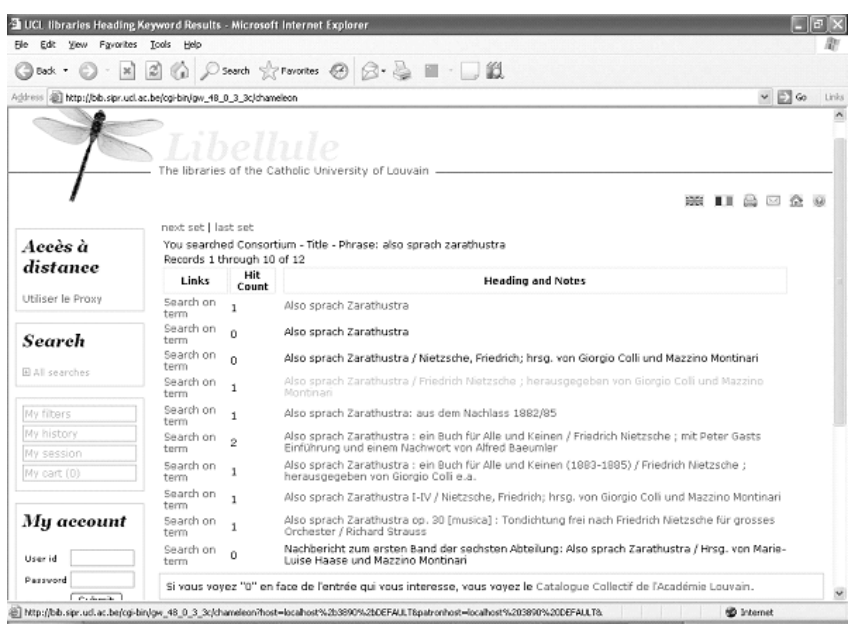

Selecting the first work yields the following screen: ... which, when FRBRized, yields a list of expressions.

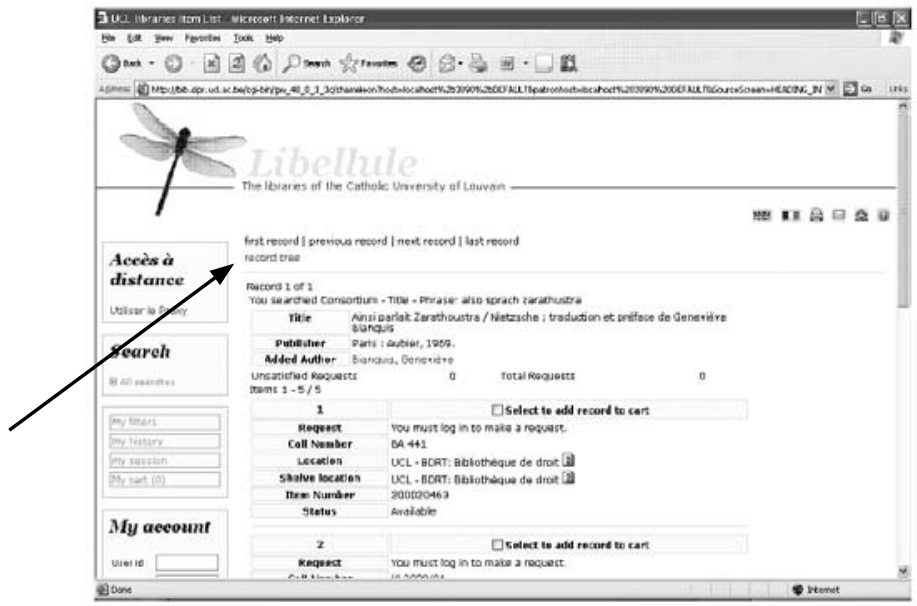

Any part of the tree may be expanded, to display manifestations, and item-level records follow.

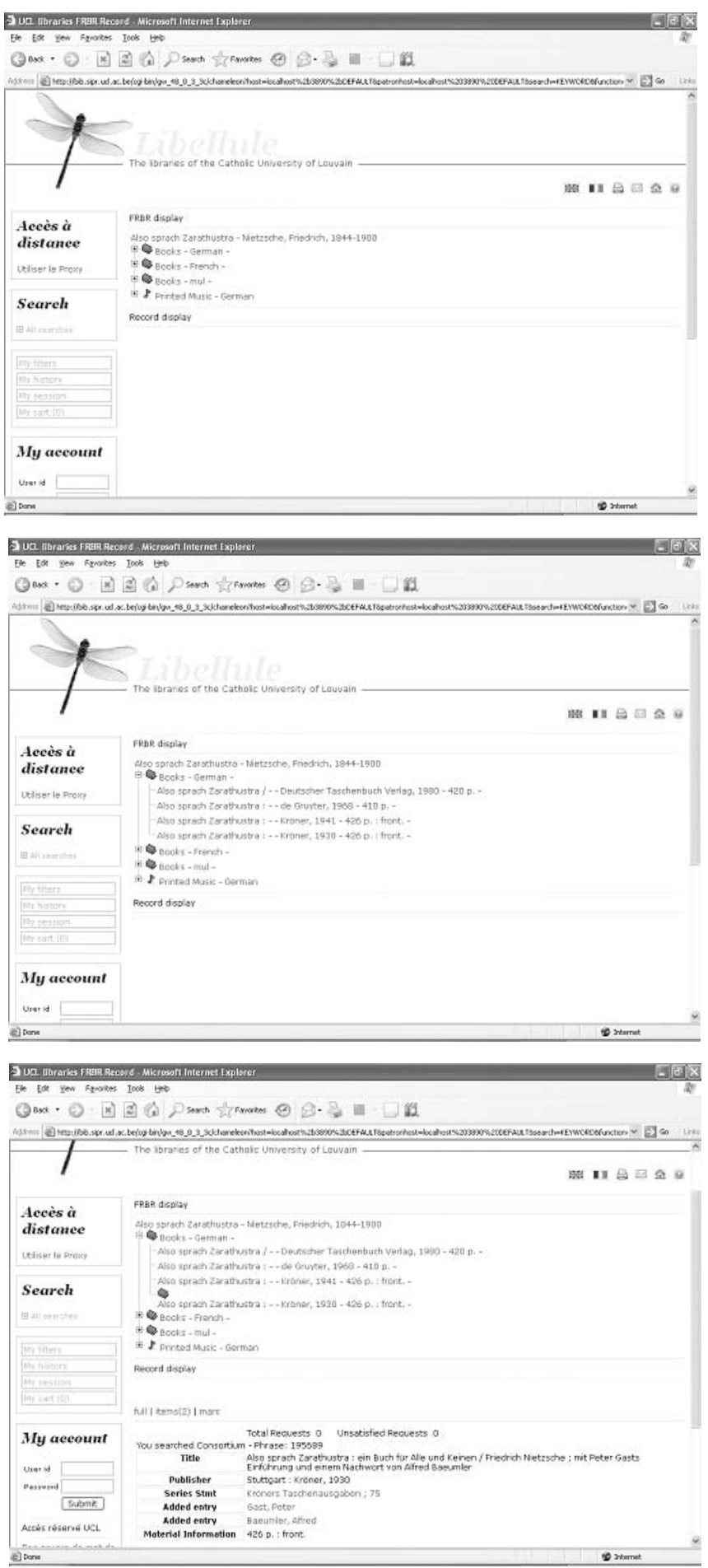

